\title{
Aberrant obturator vessels in minimally invasive pelvic lymph node dissection
}

\author{
Latchesar S. Tantchev • Grigor A. Gorchev • Slavcho T. Tomov • \\ Zdravka V. Radionova • Angelika S. Velkova
}

Received: 21 April 2013 / Accepted: 2 September 2013 / Published online: 25 September 2013

(C) Springer-Verlag Berlin Heidelberg 2013

\begin{abstract}
The presence of aberrant obturator vessels, arising from the external iliac circulatory system and their lesion during a surgical intervention in the area, may lead to bleeding, which is difficult to control. For a period of 5 years, 133 endoscopic bilateral pelvic lymph node dissections in patients with cervical cancer were performed, and the present aberrant vessels were registered and filmed. Aberrant obturator vessels were present in 58 cases $(43.6 \%)$. Eight obturator arteries and 58 obturator veins, branches of the external iliac vascular system, were visualized. Arterial type of obturator variation was found in one $(0.07 \%)$ case, venous type - in 50 (37.5\%), and combined (arterial and venous) type - in seven (5.26\%), out of all patients. Of the observed aberrant obturator arteries, three were found to arise from the inferior epigastric artery, and five from the external iliac artery. Of all available 73 veins, $51(70 \%)$ drained directly into the external iliac vein and $22(30 \%)$ in the inferior epigastric vein. The frequency of the aberrant obturator veins was $27.44 \%(n=73)$, and of the arteries $-3 \%$, related to the investigated pelvic halves $(n=266)$. The presence of aberrant obturator vessels is a relatively common anatomic variation, important for the clinical practice.
\end{abstract}

Keywords Aberrant obturator vessels · Corona mortis · Pelvic lymph node dissection

\section{Background}

Vascular anastomoses, between the obturator and the external iliac arterial and venous systems, are observed in surgical

Electronic supplementary material The online version of this article (doi:10.1007/s10397-013-0812-6) contains supplementary material, which is available to authorized users.

L. S. Tantchev $(\bowtie) \cdot$ G. A. Gorchev $\cdot$ S. T. Tomov $•$

Z. V. Radionova • A. S. Velkova

Gynecologic Oncology Clinic, Medical University_Pleven,

Georgi Kochev Str. 8a, 5800 Pleven, Bulgaria

e-mail:1_tantchev@yahoo.com interventions in the obturator and inguinal region. The lesion of the variant obturator vessels may lead to bleeding, which significantly deteriorates the view to the operative field and can seriously impede the surgical team in performing the required intervention. Minimally invasive surgical techniques allow clear visualization of the pelvic structures under optic magnification and require manipulation in bloodless environment. Knowing the anatomical variations of these vascular anastomoses, their protection or selective transection are essential for the smooth course of the retroperitoneal pelvic lymph node dissection.

\section{Materials and methods}

The present study includes 133 patients diagnosed with cervical cancer, assessed preoperatively with FIGO stage $1 \mathrm{~b} 1$. Laparoscopically assisted radical hysterectomy and pelvic lymph node dissection was carried out in 52 patients (from January 2007 to May 2008), and robot-assisted radical hysterectomy and pelvic lymph node dissection in the remaining 81 (from May 2008 to December 2011). All robotic and laparoscopic lymphadenectomies were accomplished by one surgical team, using the same operative methods. Upon resection of the round ligaments, the parietal peritoneum was opened laterally from the infundibulopelvic ligament. The proximal border of the pelvic lymph node dissection was the bifurcation of the common iliac artery and vein, and the distal border was the junction of the deep circumflex iliac vein with the external iliac vein. The inferior epigastric artery (IEA) and the inferior epigastric vein (IEV) were visualized. The superficial and the deep lymphatic chains were removed followed by isolation of the obturator nerve.

The clinical data of the patients in the two groups is presented in Table 1. There were no significant differences between the two groups $(p>0.05)$, except the lower mean age of the patients in the laparoscopic group $(p=0.001)$.

All surgical interventions were recorded and the available vascular obturator variations were registered in the course of 
Table 1 Characteristics of the patients in laparoscopic and robotic group

\begin{tabular}{lll}
\hline & Laparoscopic group & Robotic group \\
\hline Age & $40.5 \pm 9.9$ & $44.0 \pm 11.2$ \\
BMI & $24.02 \mathrm{~kg} / \mathrm{m}^{2}( \pm 5.03)$ & $24.51 \mathrm{~kg} / \mathrm{m}^{2}( \pm 6.11)$ \\
Average number of extirpated lymph nodes & $11.1 \pm 5.1($ range $3-25)$ & $11.4 \pm 7.0($ range $4-36)$ \\
Cases with metastatic lymph nodes (pN1) (FIGO IIIB) & $6(11.5 \%)$ & $15(18.5 \%)$ \\
Histology & $47(90.3 \%)$-squamous cell carcinoma & $72(88.8 \%)$-squamous cell carcinoma \\
& $5(9.6 \%)$-adenocarcinoma & $9(11.1 \%)$-adenocarcinoma \\
\hline
\end{tabular}

operation. The records were reviewed later, appropriate images were processed and by using a graphical editor, frames of the basic types of obturator vascular variations were selected. Standard statistical methods were used for data description.

\section{Findings}

In most of the cases the obturator vascular bundle was located caudally under the obturator nerve, belonging to the internal iliac vascular system. Aberrant obturator vein (AOV) draining into the external iliac vein (EIV) or the IEV was frequently visualized $(43.6 \%, n=58)$. In some cases, the vein anastomosed with the obturator vein, a branch of the internal iliac vein. Aberrant obturator artery (AOA), arising either from the external iliac artery (EIA), or the IEA, running caudally and medially, to enter with the obturator nerve the canal of the same name, were less often seen $(6 \%, n=8)$. To systematize the cases with vascular variation, a classification proposed by Rusu et al. was used to define three major types of aberrant obturator variations - arterial, venous, and combined [1]. An aberrant obturator vessel was present in 58 cases $(43.6 \%)$. There were no significant differences between the robotic and the laparoscopic group, regarding the incidence of the arterial (FET $p=$ $0.092)$ and venous $\left(\chi^{2}, 2.81 ; p=0.094\right)$ obturator anastomoses.

\section{Aberrant obturator artery}

The presence of AOA was registered in $6 \%(n=8)$ of the cases. In all the cases, the variation was unilateral. In seven of the cases with AOA, AOV was also present. In half of the patients with arterial obturator variation, the artery was located on the right side, and in the remaining four, on the left side. Of the AOAs found, three arose from the IEA (Fig. 1) and five from the EIA (Fig. 2).

\section{Aberrant obturator vein}

Aberrant obturator vein was identified significantly more often than $\mathrm{AOA}$ - in $43.6 \%(n=58)$. In $52 \%(n=30)$ of the cases, the variation was observed on the right side, in $22 \%(n=13)$ on the left side, and in $26 \%(n=15)$ in both pelvic halves.
Seventy-three aberrant obturator veins were found in all studied patients $(n=133)$. In one case, there were two AOV on the right side, one draining into the external iliac vein, and the other in the inferior epigastric vein (Fig. 3). From the available $73 \mathrm{AOV}, 51$ (70 \%) drained directly into EIV (Fig. 4) and 22 $(30 \%)$ in the IEV (Fig. 5). The frequency of AOV related to the studied pelvic halves $(n=266)$ was $27.44 \%(n=73)$.

\section{Types of aberrant obturator variations}

The frequency of the aberrant obturator vessels, divided into three main types and associated subtypes by a number of cases $(n=133)$, is presented in Table 2. In two of the cases, venous anastomoses, between aberrant obturator venous vessel, draining into the external iliac system, and a vessel draining into the internal iliac vein, were dissected (Figs. 6 and 7). Combined arterial and venous type is presented in Figs. 8, 9, and 10.

\section{Discussion}

There is a terminological diversity in defining the atypical vessels in the obturator area. Some authors define as obturator any vessel entering the obturator canal, regardless of its origin,

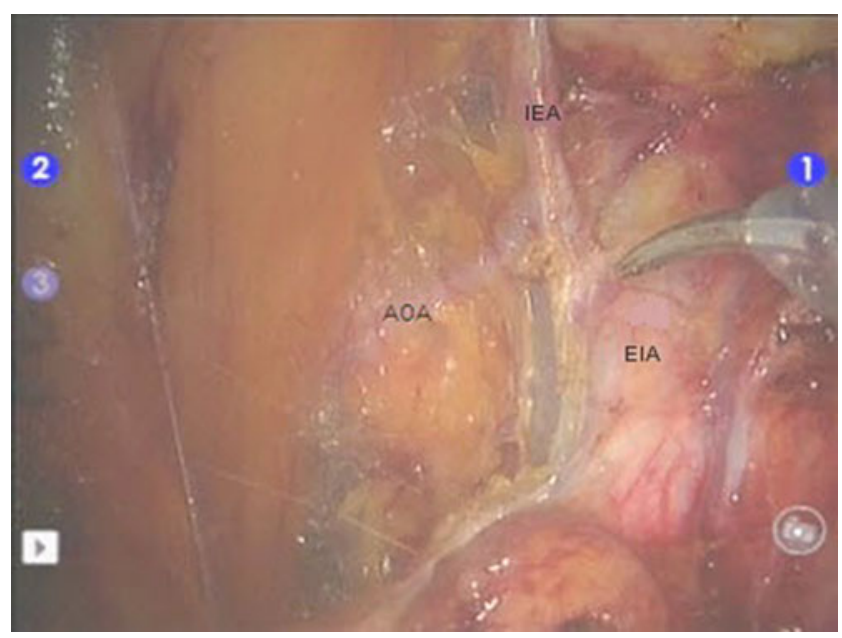

Fig. 1 The proximal part of the inferior epigastric artery (IEA) is skeletonized and the separation of the aberrant obturator artery $(A O A)$ from it is visualized (right side) 


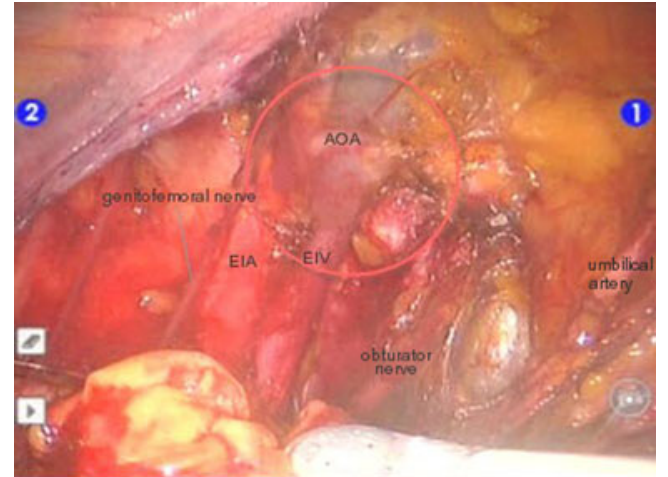

Fig. 2 Aberrant obturator artery $(A O A)$ separates from the external iliac artery $(E I A)$ between the proximal $2 / 3 \mathrm{~s}$ and distal $1 / 3$ and directs medially and caudally to the obturator canal (left side)

irrespective of its drainage [2-4]. Von Lanz and Wachsmuth term the veins passing through the obturator canal and draining into the external iliac system, "vv. comitantes" [5]. Berberoğlu et al. term accessory obturator artery/vein any anatomical variant of an obturator vessel, arising from the external iliac system [6]. Other authors prefer the term aberrant obturator vessel, used to denote any abnormal deviation [7-9]. Rusu et al. perceive the accessory as additional to another existing obturator vein, respectively artery [1]. According to them, in the absence of another obturator vessel, the only one available is the obturator artery, respectively vein, regardless of its origin and drainage. The term "aberrant obturator artery, respectively vein", describes the atypical course of the blood vessel and in this sense, an obturator vessel can be aberrant, whether arising either from the external iliac circulatory system, or entering atypically the obturator canal.

Due to conceptual differences in terminology, "aberrant obturator artery/vein" was used. The term was used to denote any vessel passing through the obturator canal and connected to the external iliac system. The obturator vessels below the obturator nerve were not always completely dissected, and it was impossible to determine whether the vessel was accessory

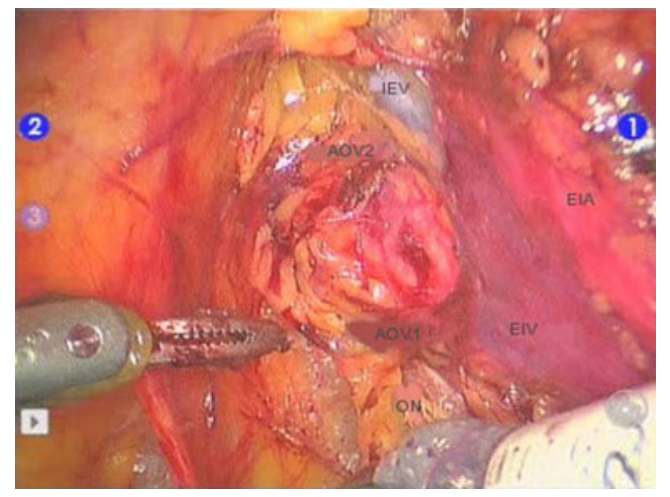

Fig. 3 Two aberrant obturator veins on the right drain in the inferior epigastric vein (IEV) (AOV1) and the external iliac vein EIV (AOV2), respectively (right side)

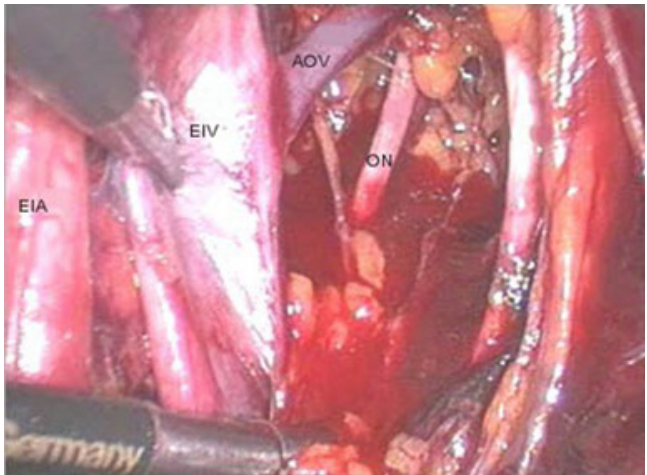

Fig. 4 Aberrant obturator vein $(A O V)$ draining in the external iliac vein (EIV) (left side)

in relation to another obturator vessel. The risk of inducing bleeding when skeletonizing the vessels in this area may impede the therapeutic and diagnostic procedure. Atypical location of the obturator nerve, artery, and vein, in relation to another one in the fossa, was not considered as aberrant obturator vessel.

The anatomical variations of the obturator vessels are an interdisciplinary problem, concerning different areas of medicine. There is a significant amount of research articles considering this topic. Some of them consider only variants of the arterial obturator vessels [10-18]. Other studies discuss the presence of venous aberrant obturator vessels as well $[1,3,4$, $6,8,9,19-23]$.

In most of the publications, data is from cadaver dissections $[1,4,9,11,14,18-24]$. In vivo results are presented only in three papers $[6,8,13]$ and a case report [15]. Two of the studies are endoscopic, in operative treatment of inguinal hernias. Karakurt et al. study AOA angiographically only in the right pelvic half [13]. Berberoglu et al., apart from a group with cadaver dissection, study a group with endoscopic extraperitoneal dissection in patients with inguinal hernia [6].

No publications concerning aberrant obturator vessels in laparoscopic or robotic transperitoneal iliac lymph node dissection are available in the literature. There were no differences between the robotic and the laparoscopic approach

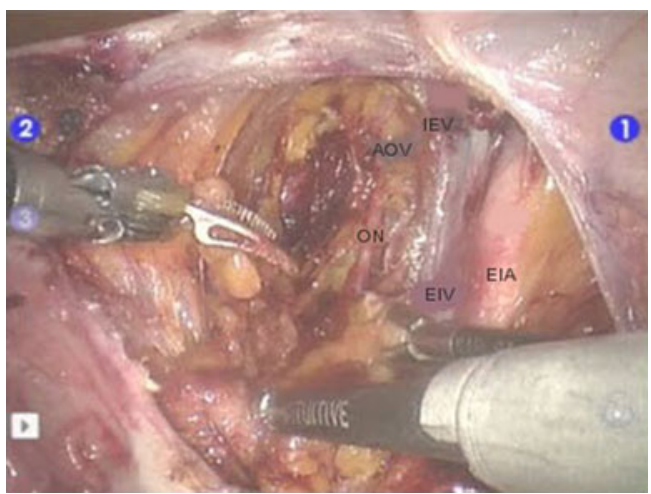

Fig. 5 Aberrant obturator vein $(A O V)$ draining in the inferior epigastric vein (IEV) (right side) 
Table 2 Frequency of the basic types of aberrant obturator vessels
$O A$ obturator artery, $O V$ obturator vein; $E I A$ external iliac artery, $E I V$ external iliac vein, IEA inferior epigastric artery, $I E V$ inferior epigastric vein

\begin{tabular}{llll}
\hline & $N$ & $\begin{array}{l}\text { \% of the cases with aberrant } \\
\text { obturator vessel }(n=58)\end{array}$ & $\begin{array}{l}\% \text { of all cases } \\
(n=133)\end{array}$ \\
\hline Arterial type & 1 & 1.72 & 0.07 \\
OA arises from EIA & 0 & - & - \\
OA arises from IEA & 1 & 1.72 & 0.07 \\
Venous type & 50 & 86.20 & 37.50 \\
OV drains in EIV & 31 & 53.44 & 23.30 \\
OV drains in IEV & 11 & 18.96 & 8.27 \\
Venous anastomosis between OV and EIV & 2 & 3.44 & 1.50 \\
Venous anastomosis between OV and IEV & 0 & - & - \\
OV drains in EIV+OV drains in IEV & 1 & 1.72 & 0.07 \\
OV drains in EIV+venous anastomosis & 3 & 5.17 & 2.25 \\
$\quad$ between OV and EIV & 1 & 1.72 & 0.07 \\
OV drains in EIV+venous anastomosis & & & 0.07 \\
between OV and EIV & 1 & 1.72 & 5.26 \\
OV drains in IEV+venous anastomosis & & & 2.25 \\
$\quad$ between OV and IEV & 7 & 12.06 & - \\
Arterial and venous variation & 3 & 5.17 & 1.50 \\
OA arises from EIA+OV drains in EIV & 0 & - & 43.60 \\
OA arises from EIA+OV drains in IEV & 2 & 3.44 & 3.44 \\
OA arises from IEA+OV drains in EIV & 2 & 100 & \\
OA arises from IEA+OV drains in EIV & 58 & & \\
Total & & &
\end{tabular}

regarding the frequency of the obturator vascular variants. This is most likely due to the lack of considerable differences in the basic patient characteristics, as well as to the fact that all interventions were performed by one team using one and the same technique.

In all cited articles, the data is based on the number of pelvic halves. Due to the fact that our study was totally clinical and the pelvic lymph node dissection performed was bilateral in all 133 cases, we processed the data in relation to the total number of patients as well.

In our opinion, determining the frequency of the anatomical variation by the number of patients studied is as important, as determining its type and frequency by pelvic halves. In the

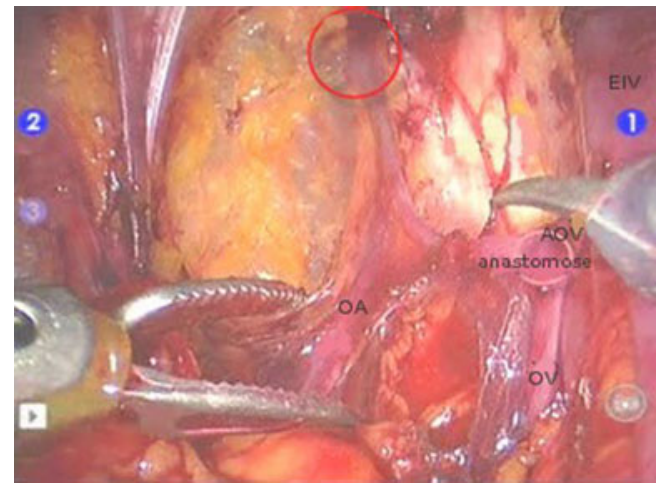

Fig. 6 Venous anastomosis between the obturator $(\mathrm{OV})$ and aberrant obturator veins $(A O V)$, draining in the internal iliac vein and the external iliac vein $(E I V)$, respectively (right side) course of the study, it was found that the classification of obturator variations, used by Rusu et al., suited our purposes [1]. The approach we adopted to calculate the frequency of the AOA/AOV types hindered the juxtaposition of data. Therefore, we calculated the frequency, not only by the number of cases, but also by the absolute number of aberrant obturator vessels in pelvic halves.

Aberrant obturator artery was found in eight cases (6\%), distributed by four, in both pelvic halves. The frequency of AOA reported is $3 \%$, related to 266 pelvic halves. The frequency of AOA ranged from $5.5 \%$ [9] to $65 \%$ [1] in the cited literature. According to Berberoglu et al., the AOA frequency is $8 \%$, which is similar to our observations [6].

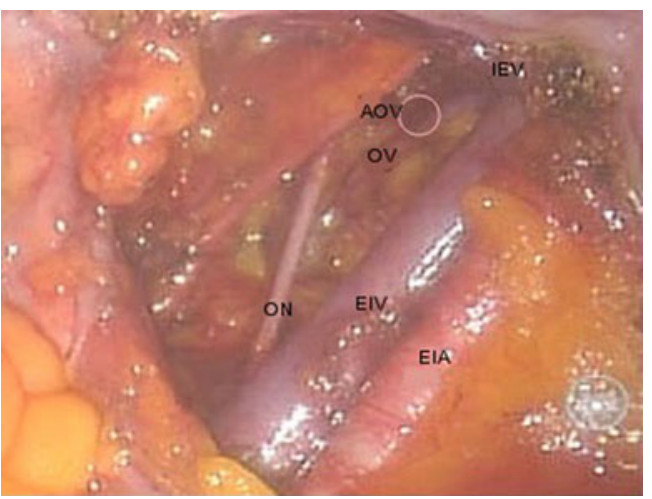

Fig. 7 Venous anastomosis between the obturator vein $(O V)$ and the inferior epigastric vein (IEV) (right side) 


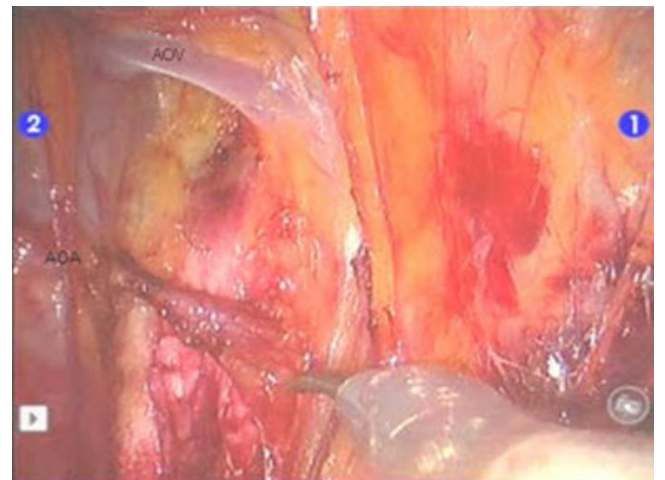

Fig. 8 Aberrant obturator artery arising from the external iliac artery $(E I A)$ and aberrant obturator vein $(A O V)$ draining in the external iliac vein (EIV) (left side)

Sarikcioglu et al. observe arterial variation more often (10\%) [4]. Other authors register AOA significantly more frequently than us $(20-30 \%)$ [8, 23, 25-27].

Of the visualized eight AOA, five originated from IEA, and three directly from EIA. The data presented by most of the authors $[1,10-12,17]$ are in favor of AOA's origin from IEA. According to others, AOA is most commonly a branch of EIA $[24,26]$. Sarikcioglu et al. have not found any case of AOA originating from IEA [4], while according to $\mathrm{M}$. Berberoglu et al., the frequency of AOA from either IEA or EIA is equal [6].

Bergman et al., in a review article, state that the unilateral presence of AOA, branch of EIA, is comparable in frequency to the bilateral variation [10]. We observed AOA unilaterally only. Another conclusion made by the authors, is that the cases with unilateral AOA, branch of IEA, are equally distributed in both pelvic halves. Our observations confirm a similar distribution pattern of AOA in the left and right pelvic halves.

Papers concerning the venous obturator variations are considerably fewer than the arterial studies, a tendency that is in dissonance with the frequency of the arterial and venous variation. Moreover, some authors even accept the existence of AOV as normal rather than an exception. Berberoglu et al. have found AOV in $96 \%$ of the cases they studied [6]. We

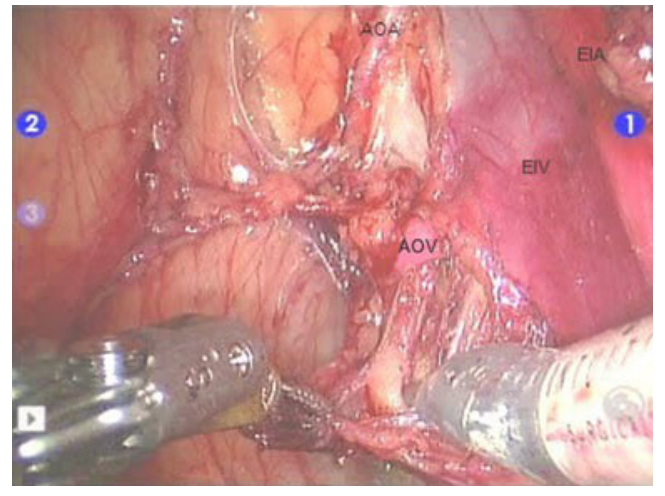

Fig. 9 Aberrant obturator artery arising from the inferior epigastric artery $(I E A)$ and aberrant obturator vein $(A O V)$ draining in the external iliac vein $(E I V)$ (right side)

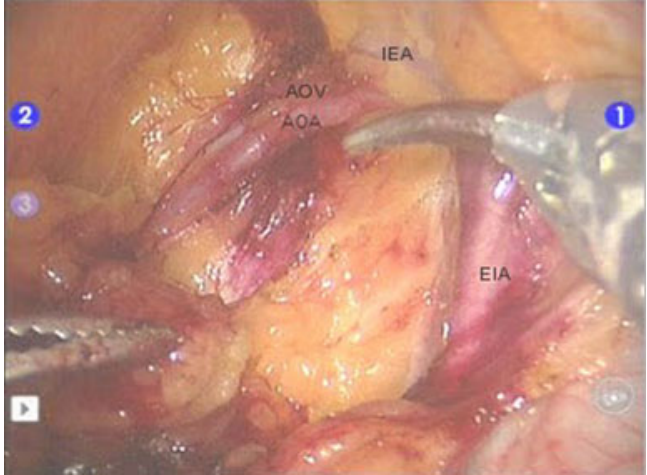

Fig. 10 Aberrant obturator artery $(A O A)$ and aberrant obturator vein $(A O V)$ originating from the inferior epigastric artery (IEA) run in parallel and drain in the inferior epigastric vein (IEV), respectively (right side)

calculated the total number of AOV (73), related to 233 pelvic halves $27.44 \%$, in order to compare our results with those of the cited authors. Our results are similar to those of Missankov et al. (26\%), Sarikcioglu et al. (20.37\%), and Lau et al. (27\%) $[4,8,24]$. In 15 (25.8\%) of the 58 cases identified with AOV, the variation was bilateral. Okcu et al. also found bilateral obturator venous variation in $25 \%$ of the cases [23].

In most of the patients, AOV was visualized only unilaterally $(43 / 74,13 \%)$, as more frequently, AOV was found in the right side $(n=30)$, and only in 13 in the left. However, Namking et al. observed approximately equally often venous variation in both pelvic halves [22]. In over half of the cases, AOV was found to drain into EIV ( $n=51 / 69.86 \%)$. Rusu et al. reported that in the pelvises they dissected, AOV was found to drain significantly more often in IEV than in EIV [1]. Other papers, describing the location of influx of AOV were not found in the available literature.

In the patients operated $(n=133)$, a venous type of obturator variation was observed most often-in $37.50 \%$ of the cases, while the arterial type was seen in only one case $(0.07 \%)$. The data of Rusu et al. are quite different from ours. Most often, they observed a combined (arterial+venous) type of obturator variation ( $40 \%$ ), and most rarely a venous type $(15 \%)$ [1]. This difference is due to the high frequency of aberrant obturator arteries in their study, unlike the ones identified in our study.

Explanation for the presence of variants of obturator arterial and venous vessels could be sought in the embryonic development of the vascular network. Definitive aberrant obturator artery is formed as a result of uneven growth of anastomoses between the external and internal iliac artery, which are connected in between by variations of the regional organogenesis. Two critical periods are distinguished in the morphogenesis of the anastomoses between the iliac arteries: renal and gonadal obstruction [27]. Obturator vessels are formed relatively late to participate in the blood supply of the lower limb. This could explain the diversity of origin and the relatively high frequency of anatomical variations. 
According to Arey and Fitzgerald, vascular anomalies are due to an unusual selection of channels from the primary capillary plexus $[28,29]$. The most appropriate channels widen, while others atrophy and disappear, thus providing the means of branching of the arterial and venous system.

\section{Conclusion}

Pelvic lymph node dissection is a basic procedure for staging and treatment of malignant gynecological diseases. The presence of aberrant obturator vessels is a relatively common anatomic variation, important for the clinical practice. Timely proceeding with the complex oncological therapy is made possible by the absence of complications in the course of surgical intervention and fast recovery of the patient. Last, but not least, the modern minimally invasive techniques, with detailed review of the retroperitoneal anatomy in vivo, may serve for educational purposes in the field of pelvic surgery.

Acknowledgments All procedures followed were in accordance with the ethical standards of the responsible committee on human experimentation (institutional and national) and with the Helsinki Declaration of 1975, as revised in 2008.

Ethical statement Informed consent was obtained from all patients for being included in the study.

Conflict of interest On behalf of all authors, the corresponding author states that there is no conflict of interest.

\section{References}

1. Rusu MC, Cergan R, Motoc AG, Folescu R, Pop E (2010) Anatomical considerations on the corona mortis. Surg Radiol Anat 32(1):17-24

2. Naguib NN, Nour-Eldin NE, Hammerstingl RM, Lehnert T, Floeter J, Zangos S, Vogl TJ (2008) Three-dimensional reconstructed contrast-enhanced MR angiography for internal iliac artery branch visualization before uterine artery embolization. J Vasc Interv Radiol 19:1569-1575

3. Saraiya PV, Chang TC, Pelage JP, Spies JB (2002) Uterine artery replacement by the round ligament artery: an anatomic variant discovered during uterine artery embolization for leiomyomata. J Vasc Interv Radiol 13(9 Pt 1):939-941

4. Sarikcioglu L, Sindel M, Akyildiz F, Gur S (2003) Anastomotic vessels in the retropubic region: corona mortis. Folia Morphol (Warsz) 62:179-182

5. von Lanz T, Wachsmuth W (1938) Practical anatomy, first volume/ fourth part [in German]. Springer, Berlin

6. Berberoğlu M, Uz A, Ozmen MM, Bozkurt MC, Erkuran C, Taner S, Tekin A, Tekdemir I (2001) Corona mortis: an anatomic study in seven cadavers and an endoscopic study in 28 patients. Surg Endosc 15(1):72-75

7. Dargent DF (1999) Laparoscopic techniques for gynecologic cancer: description and indications. Hematol Oncol Clin North Am 13:1-19
8. Lau H, Lee F (2003) A prospective endoscopic study of retropubic vascular anatomy in 121 patients undergoing endoscopic extraperitoneal inguinal hernioplasty. Surg Endosc 17:1376-1379

9. Pungpapong SU, Thum-umnauysuk S (2005) Incidence of corona mortis; preperitoneal anatomy for laparoscopic hernia repair. J Med Assoc Thai 88(Suppl 4):S51-S53

10. Bergmark K, Avall-Lundqvist E, Dickman PW, Henningsohn L, Steineck G (1999) Vaginal changes and sexuality in women with a history of cervical cancer. N Engl J Med 340:1383-1389

11. Biswas S, Bandopadhyay M, Adhikari A, Kundu P, Roy R (2010) Variation of origin of obturator artery in Eastern Indian population-a study. J Anat Soc India 59(2):168-172

12. Braithwaite $J$ (1952) Variations in origin of the parietal branches of the internal iliac artery. J Anat 86:423-430

13. Karakurt L, Karaca I, Yilmaz E, Burma O, Serin E (2002) Corona mortis: incidence and location. Arch Orthop Trauma Surg 122:163-164

14. Kawai K, Honma S, Koizumi M, Kodama K (2008) Inferior epigastric artery arising from the obturator artery as a terminal branch of the internal iliac artery and consideration of its rare occurrence. Ann Anat 190(6):541-548

15. Ebraheim NA, Liu J, Lee AH, Patil V, Nazzal MMS, Sanford CG (2008) Obturator artery disruption associated with acetabular fracture: a case study and anatomy review. Injury Extra 39(2):44-46

16. Pai MM, Krishnamurthy A, Prabhu LV, Pai MV, Kumar SA, Hadimani GA (2009) Variability in the origin of the obturator artery. Clinics (Sao Paulo) 64(9):897-901

17. Pick JW, Anson B, Ashley FL (1942) The origin of the OBA artery. Am J Anat 70:317-343

18. Sañudo JR, Roig M, Rodriguez A, Ferreira B, Domenech JM (1993) Rare origin of the obturator, inferior epigastric and medial circumflex femoral arteries from a common trunk. J Anat 183(Pt 1):161-163

19. Ersoy M, Sagsoz N, Bozkurt MC, Apaydin N, Elhan A, Tekdemir I (2004) Important anatomical structures used in paravaginal defect repair: cadaveric study. Eur J Obstet Gynecol Reprod Biol 112(2):206-213

20. Gilroy AM, Hermey DC, DiBenedetto LM, Marks SC Jr, Page DW, Lei QF (1997) Variability of the obturator vessels. Clin Anat 10(5): 328-332

21. Nagabhooshana S, Vollala V, Rodrigues V, Bhat S, Pamidi N, Lobo S (2008) Anatomical variation of obturator vessels and its practical risk: a case report from an anatomic study. J Vasc Bras 7(3):275-277

22. Namking $M$, Woraputtaporn W, Buranarugsa M, Kerdkoonchorn M, Chaijarookhanarakq W (2007) Variation in origin of the obturator artery and corona mortis in Thai. Siriraj Med J 59:12-15

23. Okcu G, Erkan S, Yercan HS, Ozic U (2004) The incidence and location of corona mortis: a study on 75 cadavers. Acta Orthop Scand 75:53-55

24. Missankov AA, Asvat R, Maoba KI (1996) Variations of the pubic vascular anastomoses in black South Africans. Acta Anat (Basel) $155: 212-214$

25. Bergman RA, Thompson SA, Afifi AK (1984) Catalog of human variation. Urban \& Schwarzenberg, Baltimore, pp 124-125

26. Jakubowicz M, Czarniawska-Grzesiñska M (1996) Variability in origin and topography of the inferior epigastric and obturator arteries. Folia Morphol (Warsz) 55:121-126

27. Petrenko VM (2000) Development of the obturator artery in human prenatal ontogenesis. Morfologiia 118(4):51-53

28. Arey LB (1963) The development of peripheral blood vessels. In: Orbison JL JL, Smith DE (eds) The peripheral blood vessels. Williams and Wilkins, Baltimore, pp 1-16

29. Fitzgerald MJT (1978) Human embryology. Harper International, New York, pp 38-56 